\title{
A Brief Analysis on the Force Majeure of Covid-19
}

\author{
Yingyuan Tang ${ }^{1,}$, Chenhao Zhao ${ }^{2}$
}

\author{
${ }^{1}$ Department of Law, Shanxi University of Finance and Economics, Taiyuan, Shanxi, 030000, China \\ ${ }^{2}$ Department of Law, Shanxi University of Finance and Economics, Taiyuan, Shanxi,030000, China \\ *Corresponding author. Email: 1208278493@qq.com
}

\begin{abstract}
To determine the legal nature of the "New Coronary Pneumonia" epidemic as force majeure, we should fully grasp its historical evolution, constituent elements, legal effects, and the difference between force majeure and situation changes, so as to get a deep reflection on the force majeure system in order to better apply and practice.
\end{abstract}

Keywords: " New Coronary Pneumonia, epidemic, force majeure, exemption

majeure system in their respective fields of civil law.

\section{INTRODUCTION}

"New Coronary Pneumonia" is called "New Coronavirus Pneumonia". The World Health Organization (WTO) named it English as Corona Virus Disease 2019 (COVID-2019). New Coronary Pneumonia takes Wuhan, Hubei as the virus center, and then spreads to the surrounding areas, so that the whole country and some countries in the world. In the medical field, experts are still in the discussion and research stage of the cause, symptoms, protective measures, treatment methods of new coronary pneumonia; but in the field of law, the author believes that it can be considered as a force majeure event. After the outbreak of the "New Coronary Pneumonia" epidemic, civil disputes broke out across the country, and people's courts at all levels were actively "preparing for" the epidemic. In order to better resolve these civil disputes, it is necessary to further analyze and explore the force majeure of the "New Coronary Pneumonia" epidemic.

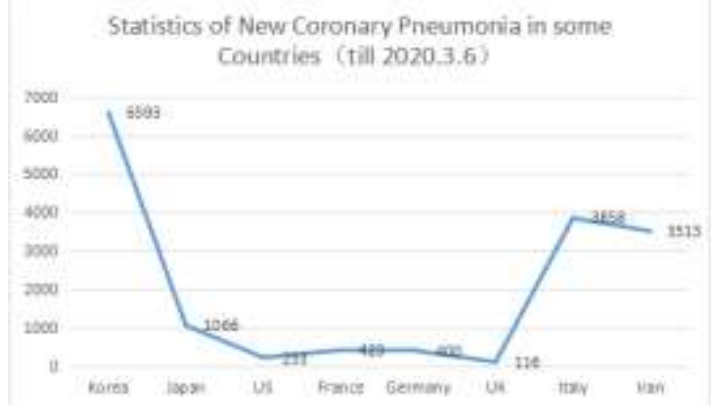

Figure1 Statistics of New Coronary Pneumonia in some Countries

\section{THE HISTORY OF FORCE MAJEURE AND RELATED REGULATIONS}

As a very common provision in the civil field-force majeure, it has a long history. Historically, countries have different interpretations and formulations of the force

\subsection{Western Countries' Historical Evolution and Regulations On Force Majeure}

The concept of force majeure originated in Roman law. If it is not the debtor 's fault or intention, but the damage caused by its unpredictable objective disaster, which leads to the loss of goods or the failure to pay, the debtor can be exempted. The force majeure provided by the Roman law refers to external facts that the perpetrator usually cannot foresee or can foresee but irresistible, such as earthquakes, tsunamis, pirates, enemy invasion, etc, and if the debtor 's consequences cannot be paid, the debtor can be exempted accordingly.

Later, the civil law system inherited and developed. First, France inherited the force majeure content of Roman law and served its legislation. For example, Article 1147 of the French Civil Code provides specific provisions on the presumption of fault, which reflects the importance attached by the civil law countries to the principle of fault liability over the Anglo-American law countries. Later, Germany based on the "French Civil Code" and developed it to create the "German Civil Code". Although the "German Civil Code" does not explicitly propose the legal term "force majeure" in the law, the force majeure situation has been explained in the actual law, and the force majeure can be inferred by specifying the conditions for the debtor to assume responsibility Exemption conditions for the situation.

Anglo-American law has long insisted on the concept of absolute obligations, and believes that a person should follow the contract he signed and perform the corresponding obligations without recognizing the force majeure system. However, with the continuous improvement and development of the rule of law and the challenge of unpredictable diversity in life, the Anglo-American legal system has also changed from adhering to the dichotomy to the trisection, but its essence and starting point are still to observe the principle of absolute obligation List exceptions on its basis and use 
them flexibly.

\subsection{The History and Regulations of China's Force Majeure}

In the modern sense, in the General Principles of Civil Law, summarizing the force majeure system as: an objective situation that cannot be foreseen, unavoidable, and insurmountable-the "three cannot" situation. The provisions of Article 117 of China's "Contract Law of the People's Republic of China" (hereinafter referred to as the "Contract Law") is the most complete discussion of force majeure system in China's laws today. To determine whether an event is force majeure, it should not only combine the general outline stipulated in the legal provisions, but also make in-depth judgments based on historical experience. Implement it so that it constitutes a corresponding situation under certain conditions.

\section{IDENTIFICATION OF THE "NEW CORONARY PNEUMONIA" EPIDEMIC AS FORCE MAJEURE}

The current scientific explanation of force majeure in our country believes that force majeure is an irresistible force of manpower, independent of human behavior, and not subject to the will of the parties. The force majeure system is briefly summarized in China's "General Principles of Civil Law" as: objective conditions that cannot be foreseen, cannot be avoided, and cannot be overcome. The following is an abstract analysis of the meaning of force majeure from the perspective of the formation of force majeure in China.

\subsection{Subjectively, Force Majeure Events Should Be Events That the Actor Cannot Foresee}

What is foresight? "Foreseeing" belongs to the actor's subjective ideological activity. There are unpredictable in all fields, whether it is the field of natural sciences, or the field of humanities. In the legal category, there are many phenomena in life that are unpredictable by actors of civil relations. Where did the foreseen standards come from? Is it the standard of the entire human race? Or is it based on the cognitive standards of the parties in the actual case? The author believes that the unforeseen standard should be the standard of public perception of ordinary people and ordinary people. As one of the conditions for the establishment of exemption, "unforeseeable" plays a vital role in the final judgment of the case. It should meet the requirements of fairness and demonstrate the essence of justice.

New Coronary Pneumonia is a sudden and widespread outbreak in the whole country and even the world. It is fierce, and its extent and impact are no less than SARS in 2003. The author believes that the "new crown pneumonia" epidemic is an unforeseen situation. Although the cause of the SARS epidemic in 2003 was similar to the cause and characteristics of the epidemic, and the "new crown pneumonia" epidemic was reported by the media after it broke out from Wuhan, Hubei, the author believes that this does not mean "new crown pneumonia" The epidemic situation is predictable. Because of the "new crown pneumonia" epidemic, people cannot accurately predict the time, scope and duration of most of its outbreaks. Although medical technology and science and technology are very advanced today, they cannot be accurately foreseen, only vaguely foreseeable, and inaccurately foreseeing does not affect the unpredictable identification of force majeure phenomena.

\subsection{Objectively, Force Majeure Should Meet Conditions That Cannot Be Avoided and Cannot Be Overcome}

Force majeure events are phenomena outside the actor They come from the outside of the actor and are independent of the actor's subjective thinking. It is very difficult to avoid and overcome the force majeure event. After the outbreak of the "New Coronary Pneumonia" epidemic, the central and local governments have adopted a series of effective and scientific measures to control the development of the epidemic. However, the rapid spread and severity of the epidemic have exceeded everyone's imagination. New Year's dinners and other activities have caused a high degree of population aggregation in a short period of time, and the incidence and infection rate of the epidemic have also increased rapidly. Although the epidemic has been controlled in the later period, reducing the infection rate and increasing the discharge rate, this does not mean that the "new coronary pneumonia" epidemic can be avoided.

\subsection{In Terms of Time, Force Majeure Shall Meet "After The Contract Is Signed, Before The Completion of the Performance"}

Force majeure is a system introduced to maintain social equity. If the epidemic situation has already occurred and various epidemic prevention and control policies have been issued in various places, the contract signed by them does not meet the "unforeseeable" conditions and it cannot be considered as force majeure. If force majeure occurs before the contract is signed, the civil legal relationship has not been established at this time, and the exemption situation will cease to exist. Problem, the force majeure cannot be brought into play. 


\subsection{The Composition of Force Majeure Should Emphasize the Causal Relationship Between the Specific Cause and the Failure or Unsuitability of the Contract}

It should be noted here that not all actions during the epidemic can be exempted according to this, and cannot be generalized. In practice, it should be judged in accordance with specific circumstances. The legal effect of force majeure events can only be produced within the scope of force majeure. If the contract cannot be performed at all or is delayed due to the occurrence of this epidemic, it is subject to force majeure, and the legal effect of force majeure applies; if it does not affect the actual performance and effectiveness of the contract, it cannot be exempted accordingly.

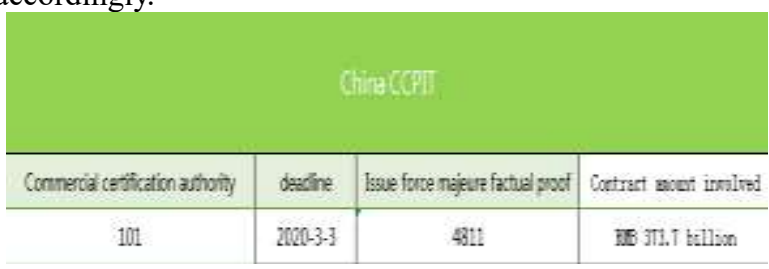

Figure 2CCPIT issues force majeure factual proof information

\section{THE LEGAL EFFECT OF THE "NEW CORONARY PNEUMONIA" EPIDEMIC AS AN EVENT OF FORCE MAJEURE}

The determination of the nature of the force majeure event is accompanied by the emergence of legal effects such as exemption, contract cancellation, and postponement of performance. In China's "General Rules of Civil Law", it is directly described as exemption from liability.

\subsection{Exemption from Liability}

Article 117 of the Contract Law provides further specific provisions on the exemption of liability. Liability exemption is divided into complete liability exemption and partial liability exemption. Part of the contract 's obligations due to the epidemic situation cannot be performed. It cannot claim to be exempted from all breach of contract liability, but can only be partially exempted from breach of contract liability.

Attention should be paid to exempting one party from the obligation of notification and proof. Article 118 of the Contract Law stipulates the notification obligation and the burden of proof. When one party to the contract is unable to perform the contract due to force majeure, it shall promptly notify the other party to the contract and provide evidence of non-performance due to the epidemic situation. Even if one party to the contract meets the applicable force majeure conditions, if it fails to notify the other party in time, it may not be able to receive support.

\subsection{Termination of the Contract}

The termination of the contract should be based on the force majeure and the inability to achieve the purpose of the contract as the standard. At this time, only one party to the contract can claim the legal right to terminate due to force majeure. For example, before the outbreak of "New Coronary Pneumonia", both parties signed a sales contract for fresh and perishable goods for the sale of bananas. Due to the long duration of the outbreak and the lack of fresh-keeping environment, the bananas have already rotted and disappeared after the outbreak. Continue to perform, at this time, one party to the contract may advocate the termination of the contract.

\subsection{Delayed performance}

Delayed performance is an important legal effect caused by force majeure. If the contract cannot continue to be performed due to the epidemic situation, then one of the contract parties can cancel the contract; if the epidemic situation only causes the contract to be temporarily unable to perform, then the contractual content can be performed in time after the epidemic is over. For example, if a large quantity of goods cannot be delivered due to the epidemic situation, the goods can still be delivered after the epidemic situation ends. If the implementation is delayed before the epidemic occurs, and the force majeure is exempted when the epidemic occurs, the claim cannot be supported at this time.

Delayed performance is an important legal effect caused by force majeure. If the contract cannot continue to be performed due to the epidemic situation, then one of the contract parties can cancel the contract; if the epidemic situation only causes the contract to be temporarily unable to perform, then the contractual content can be performed in time after the epidemic is over. For example, if a large quantity of goods cannot be delivered due to the epidemic situation, the goods can still be delivered after the epidemic situation ends. If the implementation is delayed before the epidemic occurs, and the force majeure is exempted when the epidemic occurs, the claim cannot be supported at this time.

\section{CONCLUSION}

The above is an analysis of force majeure under the epidemic of "New Coronary Pneumonia". As a relatively mature system in our civil law system, force majeure has brought a great impetus to the creation of a fair and just society ruled by law. During the anti-epidemic period, various regions have issued a series of red-headed documents on the reasonable application of the force majeure system, but force majeure should not be used as a "protection umbrella" for all civil activities. It should be analyzed according to the specific situation, straighten out the applicable standards and legal effect of force majeure in 
different situations, so that the force majeure system can play its true significance.

Although the application of the force majeure system in China has been relatively perfect, the provisions of the system are limited to the relevant departmental laws such as "General Rules of Civil Law" and "Contract Law". And specific rules are more conducive to the reasonable application in practice.

\section{REFERENCES}

[1] Zhou Nan: The Original Theory of Roman Law (Second Volume), Commercial Press 1994 Edition, 649 pages

[2] Wang Liming et al: "Civil Law", Law Press, 2008 Second edition, page 763, page 155.

[3] M. Kwiatkowska, G. Norman, D. Parker, H. Qu, Assume-guarantee verification for probabilistic systems, in: J. Esparza, R. Majumdar (Eds.), Proceedings of the International Conference on Tools and Algorithms for the Construction and Analysis of Systems (TACAS), Springer, Berlin, Heidelberg, 2010, pp. 23-37. DOI: https://doi.org/10.1007/978-3-642-12002-2_3

[4] K. Etessami, M. Kwiatkowska, M. Vardi, M. Yannakakis, Multi-objective model checking of Markov decision processes, in: O. Grumberg and M. Huth (Eds.), Proceedings of the International Conference on Tools and Algorithms for the Construction and Analysis of Systems (TACAS), Springer, Berlin, Heidelberg, 2007, pp. 50-65. DOI: https://doi.org/10.1007/978-3-540-71209-1_6 